\title{
SENSORY INTEGRATION, DESCRIPTION FEATURES AND THE TREATMENT
}

\begin{abstract}
The article describes the problem of "sensory integration", the need to study it, the peculiarities of its manifestation. Attempts are being made to draw professionals' attention to a problem that is often encountered today but is not evaluated or corrected accordingly in either children or adults. The problem is especially acute among schoolchildren. Our observations have shown that this problem may be at the root of negative educational motivation, failure to complete the curriculum, and bad behaviour. In other words, the child has an age-appropriate intellect, educated parents but exhibits bad behaviour or does not manage to educational programs. The work describes the possible signs that occur during sensory integration, as well as the case with the mentioned problem, the direction of the work aimed at overcoming it.
\end{abstract}

Keywords: Sensory integration, autism, autism spectrum, sensation, analyzer.

\section{Introduction}

The question of the classification of children's mental problems is problematic all over the world, and any deviation from the norm fits into the diagnosis of "autistic spectrum". If the problem is not clearly diagnosed, then there are difficulties in applying the appropriate correction methods. From a professional point of view, it is wrong to include children with all the incomprehensible symptoms in the autistic spectrum or, as they do in Armenia, to label them autistic, thus leaving the child and his family in uncertainty. For years, our observations have shown that people, having applied to many specialists and centres, have not been able to receive proper professional, corrective therapy. Therefore, this article is dedicated to the partial solution of this problem, which is dedicated to sensory integration, an issue that has not yet found a place in the international classification. This problem is widespread today in both children and adults.

It should be noted that sensory integration, according to the DSM International Classification (Marty \& Segal, 2015), is considered one of the characteristics of the autistic spectrum. That is to say, a child is believed to have autism spectrum syndrome if it meets the three main characteristics.

1. If there is a speech disorder 
2. There is a dysfunction of sensory integration

3. There is stereotypical behaviour.

In this article, we try to separate only the sensory integration to consider it a separate issue.

The issue of "sensory integration" was first addressed by the American ergo therapist Jean Ayres in the 1950s. His first book, "Emotional Integration and Child", published in the 1970s, explains the problem in detail. Later, his students continued his work (Ayres J. 2005).

Sensory integration is the regulation of emotions, which must then be applied in some way. Emotions give us information about the physical state of the world around us and the body. Every second, sensory information reaches our brain through five senses, the corresponding receptors. The vestibular system's work is very important, too; it helps a person perceive his own body in space.

Thus, sensory integration (Kranowitz C. S. 2012):

- It is an unconscious process that takes place in the head.

- Organizes the information received through the senses (taste, smell, sound, hearing, sight, touch, human position in space and movements).

- Gives strong senses by processing information, clearing what not to focus on (for example, listening to the teacher, not paying attention to outside noise).

- Helps to act meaningfully and to respond to the situation in which he /she/ is (adaptive response).

- Forms the basis for theoretical teaching and social behaviour (p. 9).

At school, we often meet children who have learning difficulties or even misbehaviour. Such disorders can also often be due to sensory integration dysfunction. This is evidenced by the fact that all over the world it is observed that children behave and learn badly, and their studies show that, for example, the intellect corresponds to the norms of age and they have developed polite parents too. And such a problem can be noticed only by a specialist who understands the difficulty of sensory integration. It is an automatic action for most people, which no one pays attention to, considering that it should be like digestion, breathing, etc. Experts usually notice this when the problem is deepened and complicated. Often the problem is difficult to notice even if, for example, contact with the child is not frequent. Parents can see this, but they usually do not understand what is happening to their child (Ayres J. 2005. p. 8).

Here are some signs to help parents understand if their child has this problem. 
Babies with sensory integration during infancy sit, stand, and turn late. Later, they find it difficult to tie the knots and ride a bicycle. It can be manifested by frequent falls or by constantly hitting any part of the body due to poor motor or muscle function. The problem here is not with the muscle or the nerve but with the function of the brain. That is, the information received can not be completed by the brain. In primary school, children with sensory integration disorders have poorly developed play activities. The child is not able to integrate the information that comes from the eyes, ears, hands or body, so he is not able to respond appropriately to what he sees and hears. He misses details or does not understand other people's actions. He is not attracted to games, unlike his peers, and some toys that involve manipulation can be problematic for him. Such children often get injured and break things. Impaired sensory integration can make even the simplest of actions difficult. And one of the most common manifestations of this is a speech disorder. They do not have a hearing problem but usually do not listen to the interlocutor, and the words seem to be lost somewhere. By not receiving clear information from the eyes, hands, and ears, the child performs various actions worse than one might expect, for example, cutting poorly with scissors (Kranowitz C. S. 2012, p. 12).

A is 4 years old, but he still does not speak. His parents turned to me to solve possible psychological problems related to speech. Before that, the parents had been to different specialists, but no one could say why the child did not speak. While working with the child, we noticed that the child picked stones from the sand, chewed them, licked the iron rod, ate the sand while working with beans the grains. While working with the child, we noticed that the child climbed very high places very easily, not always. That is, he lifted his bodyweight very easily. Still, when walking, we noticed an asymmetry of foot and hand movements. He often closed his eyes and opened them. Combining all this, we can see that the child has a dysfunction of sensory integration, that is, the fact that the child chews dirt, sand and stone, is related to the sense of taste.

It should be noted that the mother complained about the food, that the child did not eat soft, slimy food, he refused. Often the strong closing of the eyes is connected with the visual sensation, and the problem with the muscular, big or small motor skills is associated with the corresponding receptors. At first, the child was very disgusted with touching the sand, then we taught him, which is related to the sensation of touch. I think the child also has a problem with the sense of hearing, because of which he cannot understand the words correctly in order to learn the word. After running, he often could not keep his balance, which is a problem with the vestibular system. 
In fact, the problem here is not in the senses but in the brain, which must analyze the information received from the senses and integrate it, which is broken in the child. Examining children with different problems, we noticed that this problem, to varying degrees, is present in many children, which does not allow them to adequately perceive, analyze information from the outside world, and respond appropriately. Trying to find the reasons for the event, we noticed that most of them spend a lot of time watching computer games, videos, TV shows. Thus, it can be concluded that the problem is the sedentary life of children, mainly the long viewing of different tablets, which affects both physiology and psyche. It is also very interesting to work on the correction, which is so brilliant, at the same time very simple.

\section{Psychological Intervention}

We have carried out psychological intervention to work and activate all the senses as much as possible. Because we think that a child has an emotional hunger, that is why he exhibits strange behaviour from the outside, such as chewing on a stone. In fact, these children have a strong need to feel intense emotions. They have two extremes. They are sometimes very sensitive to external stimuli and sometimes, on the contrary, have no sensitivity. It often confuses adults. They may feel a slight pain from the touch of a light hand, but after a while, they may not feel pain even from a decisive blow. This is again explained by the fact that the brain does not adequately analyze the information received from the muscle. Since the problem is in signal analysis, we think it would be proper to direct strong signals from different analyzers: light, sound, taste, smell, touch, and as much as possible. As well as work with proprioceptors, that is, to affect the muscle, often giving weight to the child and developing the vestibular system. Let's present the work in these directions in more detail.

We used the following method to stimulate the signals received from the muscles. We suggested that the child carry weights both during our work and during the day. The goal is for the baby to feel its muscle and gradually gain weight to get a more vital impulse to the brain. Nursing also works effectively here. We take a large piece of cloth and wrap it so that the person can hardly get out of it. Note that the diaper actually gave that feeling; it develops the muscular sensation, helps the person to feel his body. He can also generate tremendous or small motor skills. For this, you need physically active games running, climbing stairs, jumping. And for the development of small motor skills, you need to actively work with your hands, for which there are games and toys. 
To develop tactility, you need to work with the child on materials like sand, clay, dough, hydrogel, various granules.

For hearing, music therapy should be performed together with efforts of developing the vascular system. This is an organ system in the ear that is responsible for perceiving a person's place in space. That is, if it is poorly developed, the child does not perceive his body in space. If the child does not perceive and feel his body, he can not perceive himself nor another person's boundaries; therefore, he can not keep the border between other people and communicate with them. This also means that he can hit the other person and not realize that he has hurt him. In other words, regular human-tohuman communication is conditioned by the healthy operation of this system. And to develop this system, the child needs a lot of swinging. The baby crib, the swing, best contribute to the development of the vestibular system, which in turn affects the development of attention and memory.

For a sense of taste, it is recommended that the child often chew solid foods, cookies and often use sour foods.

For the smell, we used materials in the games that contributed to both the development of the corresponding centres of touch and smell. For example, playing with coffee beans

and plastering with ground coffee, playing with cloves, we sometimes used fragrant plants such as cinnamon, mint, nutmeg.

We used colour-light therapy, as well as Isotherapy, to develop our sense of sight.

It is also essential to develop self-care skills for the child. Work has also been done in this direction (Cvetkova G.E. 2016).

Feldenkrais method. Feldenkrais is one of the most famous scientists in bodyoriented therapy. His approach works very well with children. It seems to be a bridge between the body, or rather the muscle and the brain. Working with this method leads to the fact that the change in the stereotypical action of the muscle in the brain leads to new connections, new activation, which in turn leads to positive changes in human behaviour and psyche. We have seen positive results in correcting sensory integration with this method (Feldenkrais M. 2001, p. 45).

\section{Conclusion}

Thus, we think that psychological work with children should include active physical games, but we should approach it literally, consciously, understanding exactly what emotional-cognitive result we expect. Sedentary methods that ostensibly develop attention or memory are not very effective, and the child should do as much physical 
activity as possible, sit on a swing, play in the sand to grow up healthy both physically and mentally.

\section{References}

Ayres J. (2005). Sensory Integration and the child: 25 Anniversary. Western Psychological Services.

Cvetkova G.E. (2016). Farmirovanie navikov samoobsludzivaniya u detey i podrostkov s problemami razvitiya. Metodicheskoe posobie (The formation of selfservice skills in children and adolescents with developmental problems. Methodical guide). Saint-Petersburg.

Feldenkrais M. (2001). Soznanie cherez dvijenie; dvenacat prakticheskix urokov (Awareness Through Movement: Twelve Practical Lessons). Moscow. https://www.researchgate.net/publication/283296361 DSM-

5 Diagnostic and Statistical Manual of Mental Disorders

Kranovic K.S. (2012). Razbalansirovanniy rebenek (The Out-Of-Sync Child). SaintPetersburg.

Marty, M. A., \& Segal, D. L. (2015, January 1). DSM-5: Diagnostic and Statistical Manual of Mental Disorders. ResearchGate. 